\title{
Many-Objective Optimization of Sustainable Drainage Systems in Urban Areas with Different Surface Slopes
}

\author{
Omid Seyedashraf $^{1} \cdot$ Andrea Bottacin-Busolin $^{1}$ (D) Julien J. Harou ${ }^{1,2}$
}

Received: 21 October 2020 / Accepted: 12 April 2021/ Published online: 9 June 2021

(C) The Author(s) 2021

\begin{abstract}
Sustainable urban drainage systems are multi-functional nature-based solutions that can facilitate flood management in urban catchments while improving stormwater runoff quality. Traditionally, the evaluation of the performance of sustainable drainage infrastructure has been limited to a narrow set of design objectives to simplify their implementation and decision-making process. In this study, the spatial design of sustainable urban drainage systems is optimized considering five objective functions, including minimization of flood volume, flood duration, average peak runoff, total suspended solids, and capital cost. This allows selecting an ensemble of admissible portfolios that best trade-off capital costs and the other important urban drainage services. The impact of the average surface slope of the urban catchment on the optimal design solutions is discussed in terms of spatial distribution of sustainable drainage types. Results show that different subcatchment slopes result in non-uniform distributional designs of sustainable urban drainage systems, with higher capital costs and larger surface areas of green assets associated with steeper slopes. This has two implications. First, urban areas with different surface slopes should not have a one-size-fits-all design policy. Second, spatial equality must be taken into account when applying optimization models to urban subcatchments with different surface slopes to avoid unequal distribution of environmental and human health co-benefits associated with green drainage infrastructure.
\end{abstract}

Keywords Sustainable urban drainage systems · Many-objective optimization - Catchment slope Spatial equity $\cdot$ Low impact development

Andrea Bottacin-Busolin

andrea.bottacinbusolin@manchester.ac.uk

1 Department of Mechanical, Aerospace and Civil Engineering, The University of Manchester, Sackville Street, M13 9PL, Manchester, UK

2 Department of Civil, Environmental \& Geomatic Engineering, University College London, Gower Street, London WC1E 6BT, UK 


\section{Introduction}

Global climate change, rapid expansion of cities, and the aging of existing urban drainage infrastructure raise new challenges for urban flood management (Raei et al. 2019; Arfa et al. 2021). The accelerated conversion of undeveloped areas into residential and commercial areas has altered the natural water cycle, resulting in extreme flood events, groundwater shortages, and pollution of receiving water bodies as stormwater runoff picks up pollutants from urban surfaces (Abou Rjeily et al. 2017, 2018; Luodan et al. 2019; Zhang et al. 2020). Sustainable urban drainage systems, also referred to as low impact developments, green infrastructure, and best management practices (Fletcher et al. 2015), are multi-functional nature-based urban drainage solutions, which can be used to mitigate the environmental impact of urbanization. Conventional urban drainage systems are designed for rapid drainage of stormwater runoff. However, sustainable drainage systems are designed to facilitate the detention, infiltration, and evapotranspiration process of stormwater runoff while removing diffuse pollutants (Tang et al. 2021; Geberemariam 2021).

The design of sustainable urban drainage systems is a daunting task due to their inherent hydrological and hydraulic complexity together with the conflicting stakeholder interests that often characterize urban planning (Horgan and Dimitrijević 2019). Traditionally, drainage systems have been designed using trial-and-error approaches resulting in poor project outcomes that often fail to achieve an appropriate balance of community's interests. To overcome this problem, researchers have linked rainfall-runoff simulation models with multi-objective optimization methods for multi-dimensionally efficient ('Pareto-optimal') urban drainage system designs. By exploring discrete and continuous systems while satisfying problem constraints, multi-objective evolutionary algorithms have proven effective in facilitating urban drainage system design ( $\mathrm{Li}$ et al. 2015, 2019; Riaño-Briceño et al. 2016; Martínez et al. 2018; $\mathrm{Xu}$ et al. 2018; Banihabib et al. 2019). Several studies have applied evolutionary algorithms to the optimization of sustainable drainage design taking into account up to three objectives, including minimization of capital cost, flood volume, and total suspended solids as proxies for flood damage and stormwater pollution, respectively (Ghodsi et al. 2016; Eckart et al. 2018; Latifi et al. 2019; Xu et al. 2020). For example, Ghodsi et al. (2016) linked the Non-dominated Sorting Genetic Algorithm II (NSGA-II) with the Storm Water Management Model (SWMM) to optimize the design of sustainable urban drainage systems. The combination was used along with a bargaining approach to handle several stakeholders' deliberations in the decisionmaking process. Duan et al. (2016) linked the same hydrodynamic simulation model with the particle swarm optimization algorithm and applied the framework to find a set of Paretooptimal locations of detention tanks and sustainable infrastructure facilities for a real case study located in China. Giacomoni and Joseph (2017) applied the NSGA-II optimization model to find an efficient spatial distribution of green roofs and permeable pavements in an idealized case study. Later, Eckart et al. (2018) implemented the Borg multi-objective evolutionary algorithm (Hadka and Reed 2013), to optimize surface areas of rain gardens, permeable pavements, and infiltration trenches in an urban catchment in Windsor, Canada. Alves et al. (2019) investigated benefits of synergetic use of green, blue, and grey drainage infrastructure facilities for flood management designs. They showed that flood mitigation objectives and environmental co-benefits of sustainable drainage infrastructure must be jointly taken into account in optimization models to maximize efficiency of sustainable urban drainage systems. This needs to consider the relative efficiency of grey and green drainage infrastructure in reducing flood damage and stormwater pollution (Yang and Zhang 2021), in line with the 
findings by Leng et al. (2021) which demonstrate the benefits of synergistic implementation of grey and green infrastructure as well as the superiority of the latter in providing environmental benefits. Hou et al. (2019) used a combination of the p-median model and the ant colony optimization algorithm based on amount of on-site harvested rainwater, to find an efficient sustainable drainage design. Lu and Qin (2019) also proposed a combination of the genetic algorithm and fuzzy simulation while considering uncertainties in reducing total flood volume in urban catchments. Taking into account the impacts of climate change on rainfall intensities, Ghodsi et al. (2020) considered the average peak runoff as an optimization objective in an integrated framework to find efficient designs of sustainable drainage infrastructure. More recently, Taghizadeh et al. (2021) linked the Storm Water Management Model with a multiobjective particle swarm optimization model to find efficient spatial distributions of permeable pavement, infiltration trenches, and bioretention cells to reduce pollutant concentrations in an urban area north west of Tehran, Iran.

Despite the extensive literature on the subject, most of the simulation-optimization studies address one to three design goals, which are insufficient to comprehensively assess the cobenefits of sustainable drainage infrastructure. Moreover, there is still a paucity of insight into the effect of the average surface slope on the spatial distribution of sustainable drainage system components when this is determined using optimization models. The importance of this lies in the fact that subcatchment slopes can affect the pattern of stormwater detention and infiltration resulting in a biased distribution of floods in cities with various topographic features. Accordingly, when using an optimization model on this subject, the search algorithm may find a sustainable drainage system cost-effective where specific drainage system components are allocated to particular subregions. Although the optimization solution may be efficient in terms of flood management, it can raise concerns about social justice and spatial equality, one of the pillars of the sustainable development goals, in urban drainage system design (Zheng et al. 2020; Taguchi et al. 2020).

This study shows how the average surface slope of urban catchments can impact equality in the spatial distribution of sustainable drainage components in urban areas if an optimization model is used to support design decisions. To this end, we apply a many-objective optimization approach to a synthetic case study under different slope scenarios. We introduce parallel axis plots laid alongside system design maps as a summary graphical representation of optimization results for stakeholder deliberations. Results show that urban areas with varying slopes within the same catchment should not have a one-size-fits-all sustainable drainage design. At the same time, care should be taken in ensuring that differences in average surface slope do not result in an unequal distribution of co-benefits associated with green drainage infrastructure.

\section{Methods}

\subsection{Hydraulic Simulation Model}

The simulation of an urban drainage system requires a rainfall-runoff and hydraulic routing model. In this study, the simulations were carried out using the Storm Water Management Model (SWMM) developed by the U.S. Environmental Protection Agency (Rossman 2017), which can simulate rainfall, runoff, infiltration, pollution transport, and drainage process in closed- and open-channel conduits (Rossman and Huber 2016). This numerical model can perform flow routing simulations using the steady flow, kinematic wave, or dynamic wave 
method (Rossman 2017). In this study, the dynamic wave routing method was used, which allows simulation of open-channel flows with backwater effects as well as pressurized flow in drainage pipes. This routing model solves the full one-dimensional Saint-Venant equations (Rossman 2017):

$$
\begin{gathered}
\frac{\partial A}{\partial t}+\frac{\partial Q}{\partial x}=0 \\
\frac{\partial Q}{\partial t}+\frac{\partial\left(Q^{2} / A\right)}{\partial x}+g A \frac{\partial H}{\partial x}+g A S_{f}+g A h_{L}=0
\end{gathered}
$$

where $t$ is time, $x$ is the distance along the pipe, $A$ is the flow cross-sectional area, $Q$ is flow discharge, $g$ is gravitational acceleration, $H$ is the hydraulic head, $S_{f}$ is the friction slope, and $h_{L}$ is the local energy loss per unit length of conduit.

\subsection{Sustainable Drainage Assets}

The sustainable drainage assets considered in this study include permeable pavements, infiltration trenches, bio-retention cells, rain gardens, rain barrels, and green roofs. Since each of these assets has different performance characteristics, their efficient combination can help achieve an effective design for a specific urban drainage system (Leng et al. 2021; Yang and Zhang 2021). For instance, conventional asphalt and concrete pavements may be replaced by permeable paving materials, which are generally made of a pervious layer laid on a stone reservoir, or interlocking pavers to enhance infiltration. This can reduce stormwater runoff by enhancing infiltration and disposing of the excess runoff (Hu et al. 2018). Moreover, infiltration trenches may be employed as storage pits to reduce the runoff by improving water retention and infiltration. Bio-retention cells and rain gardens may also be used to facilitate the infiltration rate and boost groundwater recharge while enhancing stormwater quality (Rossman 2017). Rain barrels and cisterns are useful to temporarily detain runoff and limit its flow into gutters to reduce pressure imposed on the drainage system. Furthermore, green roofs can slow down, absorb, retain runoff, reduce the energy use of buildings, increase the life of roofing systems, and regulate building temperature (Bolliger and Silbernagel 2020). Given their different properties and performance in terms of decreasing flood volume and stormwater pollution, cost-effective combination and spatial distribution of these assets are desirable.

\section{Model Application}

\subsection{Case Study}

A 29-ha synthetic urban drainage system case study with 8 subcatchments, 13 junctions, and 13 conduits, was selected to demonstrate the design formulation described above and investigate the relationship between average surface slope and drainage element performance (Fig. 1). We consider three average surface slopes: $0.01 \%, 3 \%$, and $6 \%$.

A synthetic 100-year, 2-h hyetograph with 5-min increments was defined using the Alternating Block Method as an extreme rainfall event. The impervious surfaces were assumed to be composed of rooftops and driveways with equal ratios of surface areas. Two land-use 


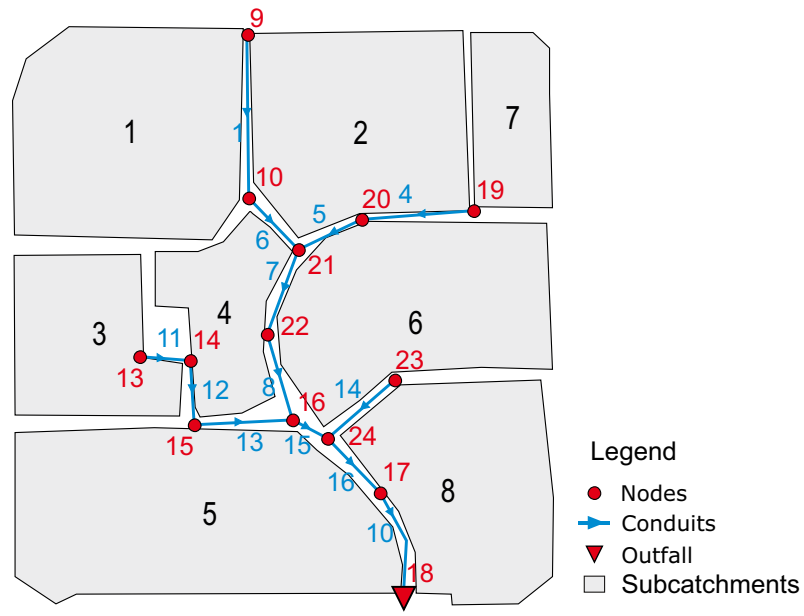

Fig. 1 Schematic map of the synthetic case study

classifications were defined, including residential and undeveloped areas, and the Event Mean Concentration method was applied to estimate wash-off load of total suspended solids. To maximize efficiency of the sustainable drainage system, the decision variables consider combinations of two sustainable drainage types and their surface areas, represented by four integer values in each subcatchment. The surface area of the sustainable drainage components was parameterized as a percentage of the impervious surfaces in each subcatchment. The maximum allowable surface area was set to $15 \%$ of the impermeable area of each subcatchment. The area of the subcatchments, land coverage and slope scenarios are summarized in Table 1.

We link the Controlled NSGA-II (CNSGA-II) (Deb and Goel 2001; Deb et al. 2002) optimization algorithm to the Storm Water Management Model. NSGA-II is a fast, elitist multi-objective genetic algorithm, which is commonly used in different water engineering and urban infrastructure problems (Khorshidi et al. 2018; Manocha and Babovic 2018; Alamdari and Sample 2019). The CNSGA-II additionally controls the extent of elitism while favoring individual vectors that can increase diversity of the population in the optimization process (Deb and Goel 2001).

Table 1 Subcatchment settings for the case study

\begin{tabular}{|c|c|c|c|c|c|c|}
\hline \multirow[t]{2}{*}{ Subcatchment } & \multirow[t]{2}{*}{ Surface area (ac) } & \multicolumn{2}{|l|}{ Coverage } & \multicolumn{3}{|c|}{ Average surface slope $(\%)$} \\
\hline & & Residential & Undeveloped & Scenario 1 & Scenario 2 & Scenario 3 \\
\hline $\mathrm{S} 1$ & 10 & $100 \%$ & - & 0.01 & 3 & 6 \\
\hline $\mathrm{S} 2$ & 10 & $100 \%$ & - & 0.01 & 3 & 6 \\
\hline $\mathrm{S} 3$ & 5 & $100 \%$ & - & 0.01 & 3 & 6 \\
\hline S4 & 5 & $100 \%$ & - & 0.01 & 3 & 6 \\
\hline S5 & 15 & $75 \%$ & $25 \%$ & 0.01 & 3 & 6 \\
\hline S6 & 12 & $100 \%$ & - & 0.01 & 3 & 6 \\
\hline S7 & 4 & $100 \%$ & - & 0.01 & 3 & 6 \\
\hline S8 & 10 & $50 \%$ & $50 \%$ & 0.01 & 3 & 6 \\
\hline
\end{tabular}




\subsection{Many-Objective Optimization Model Formulation}

As mentioned, several simultaneous benefits may be sought in sustainable urban drainage infrastructure design related to efficiency of a drainage system in reducing flood damages and improving its environmental performance (CRC for Water Sensitive Cities 2016; Horton et al. 2016; Macro et al. 2019). For example, urbanization increases the impermeable surface area of catchments and therefore increases the potential flood volume, flood duration, and peak runoff rate, which requires a drainage system with a large capacity and therefore higher capital cost. A higher average peak runoff rate can increase surface erosion and stormwater pollution by washing sediments and pollutants off the catchment surface. To handle these design objectives, a many-objective optimization model can be used to reach a set of efficient solutions while satisfying various design objectives and constraints.

In this paper, the following five objective functions are considered:

$$
\text { Minimize } \mathbf{F}(\boldsymbol{\theta})=\left(F_{\text {Cost }}, \quad F_{\text {FloodV }}, F_{\text {FloodD }}, F_{\text {PeakR }}, F_{\text {TSS }}\right)
$$

where $\theta$ is the vector of decision variables, $F_{\text {Cost }}$ is capital cost, $F_{\text {FloodV }}$ is total flood volume, $F_{\text {FloodD }}$ is flood duration, $F_{\text {PeakR }}$ is peak runoff, and $F_{\text {TSS }}$ is total suspended solids (TSS).

The capital cost was calculated for the urban catchment as follows:

$$
\mathrm{F}_{\text {Cost }}=\sum_{\mathrm{i}=1}^{n_{s}} \sum_{j=1}^{1}\left(\mathrm{c}_{i j} \times \mathrm{a}_{i j}\right)
$$

where $n_{s}$ is the number of subcatchments, $l$ is the number of sustainable drainage system types in each subcatchment, and $a_{i j}$ and $c_{i j}$ are the surface area and capital cost of each drainage component, respectively. The capital costs for the drainage assets were extracted from databases published by Herrera Environmental Consultants (2012) and online vendors.

The total flood volume is defined as:

$$
F_{\text {FloodV }}=\sum_{i=1}^{n} F V_{i}
$$

where $n$ is the number of manholes and $F V_{i}$ is flood volume at the $i$-th manhole.

The average manhole flood duration in the urban catchment is defined as:

$$
\mathrm{F}_{\text {FloodD }}=\frac{\sum_{\mathrm{i}=1}^{\mathrm{n}_{\mathrm{f}}} \mathrm{FD}_{\mathrm{i}}}{\mathrm{n}_{\mathrm{f}}}
$$

in which $F D_{i}$ is flood duration at the $i$-th manhole and $n_{f}$ represents the number of flooded nodes.

Peak runoff is defined as:

$$
\mathrm{F}_{\text {PeakR }}=\frac{\sum_{\mathrm{i}=1}^{n_{s}} \mathrm{P}_{\mathrm{i}}}{\mathrm{s}}
$$

where $P_{i}$ is the peak runoff in each subcatchment.

Finally, the overall total suspended solids (TSS) load was extracted from the numerical results.

To represent the locations of sustainable drainage components, the crossover, mutation, and reproduction operators in the genetic algorithm were adapted to produce integer-valued individuals. Moreover, as an optimization constraint, solutions with two identical sustainable 
drainage types in each subcatchment were flagged as infeasible solutions. This, however, does not prevent the model from finding solutions with just one type of sustainable drainage systems or even a no-intervention option in a subcatchment, as these can be obtained by selecting the no-intervention option or zero surface area for sustainable drainage assets. The population size of 200 was selected based on a crowding spread study. A function tolerance of $10^{-3}$ for 100 consecutive iterations was used as the stopping criterion, which resulted in around 22,000 function evaluations before the optimization stopped.

\section{Results and Discussion}

Many-objective optimization allows analysts and their stakeholder clients to identify Paretooptimal engineered water system designs and their performance trade-offs considering multiple metrics of performance. The term "many-objective" (Fleming et al. 2005), refers to an optimization model with four or more objectives. This high dimensionality means effective multi-criteria visualization techniques must be used to help identify designs that best satisfy stakeholder design goals. The multi-objective optimization approach used here focuses on the a posteriori optimization (Zatarain Salazar et al. 2017), i.e., weights do not have to be assigned to objectives a priori (i.e., before seeing results). This means stakeholders can develop their own views about the relative importance of design criteria by assessing the impact of favoring one performance metric over another and seeing the impact these varying priorities have on drainage design. This deliberative design process could be enhanced by using interactive versions of the plots below.

To illustrate here how a range of high-value designs can be extracted from the Paretooptimal solution set provided by the many-objective optimization, we look at three example design solutions that correspond to alternative sets of stakeholder priorities. The first set of priorities selects the least-cost drainage system design that fits within a prescribed range of acceptable flood volume and flood duration. Such a design might be sought if priority is given to reducing flood damages and securing normal transportation traffic near flooded manholes. The second design selects the least-cost option amongst designs that fit within a prescribed range of flood volume and average peak runoff. Finally, a third design option is chosen which corresponds to the least-cost option that meets a given constraint on the total suspended solids.

Figure 2 presents a five-dimensional plot of the Pareto front for $0.01 \%, 3 \%$, and $6 \%$ average surface slopes. Flood volume, total suspended solids, and flood duration are shown on the $\mathrm{x}, \mathrm{y}$, z-axes, and capital cost and average peak runoff are represented by the color and the marker size, respectively. The green-to-blue color scale represents low-to-high capital costs and larger markers represent larger average peak runoff values. The five-dimensional plot in Fig. 2 provides an overview of the system performance with respect to the various performance metrics. The figure shows that the variation in flood volume and flood duration for the $0.01 \%$ slope is smaller than that of $3 \%$ and $6 \%$ slopes. The graphs also show that higher flood volumes are not necessarily associated with higher flood durations.

Although these plots are accurate and complete, they do not lend themselves easily to urban stakeholder learning and design deliberation. To enable this, we use parallel axis plots (Inselberg 2009) and present them beside system design schematics. This allows exploring trade-offs between the optimization objectives and their implications on spatial design as illustrated in Figs. 3, 4, and 5 for the three surface slope scenarios. In these plots, each axis represents a different objective function, and each line connecting the axes 

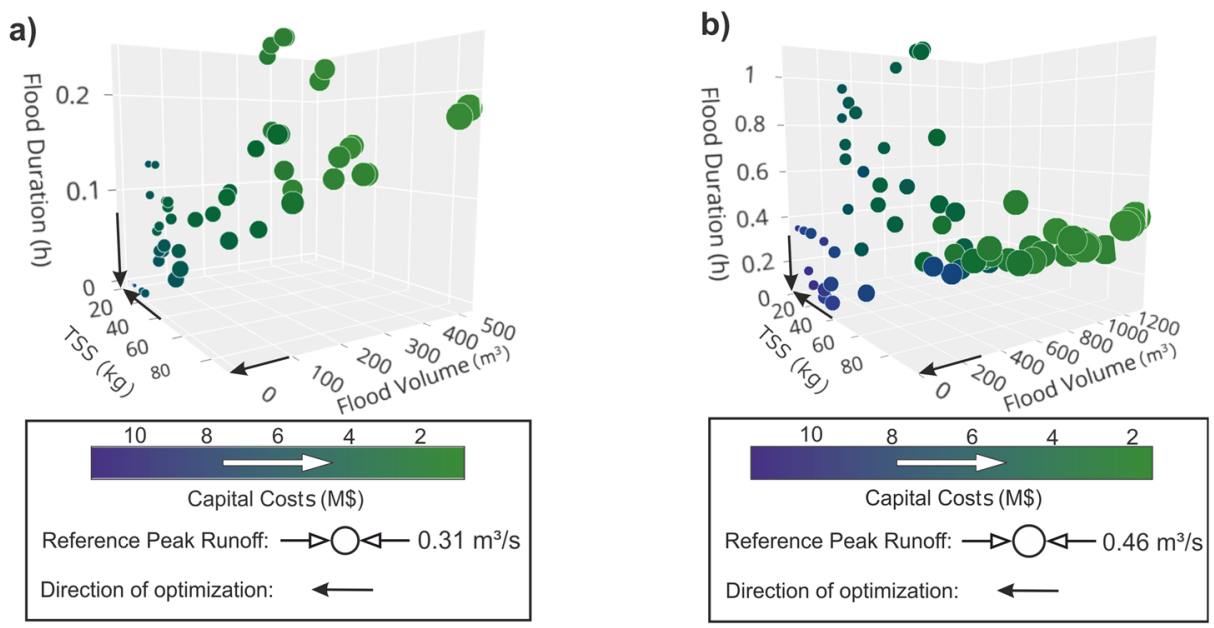

c)

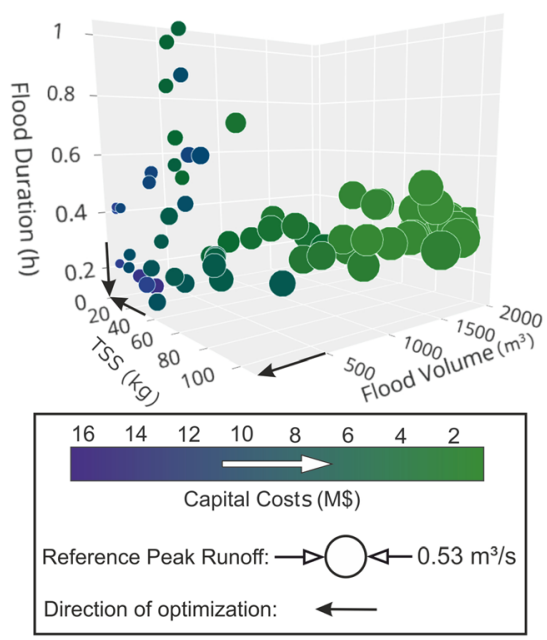

Fig. 2 Five-dimensional representation of the Pareto-front for the selected case study considering three surface slope scenarios including (a) $0.01 \%$ slope, (b) 3\% slope, and (c) 6\% slope (Table 1). The green-to-blue color scale represents low-to-high capital costs and marker sizes are proportional to the average peak runoff values in each scenario. The graphs show that higher flood volumes are not necessarily associated with higher flood durations

represents the performance of a particular non-dominated portfolio of interventions. This visualization technique allows the user to interactively select the set of solutions that satisfy given post-optimization constraints for each objective in the plot. Figures 3, 4, and 5 show the performance of the non-dominated optimal solutions for the case of $0.01 \%, 3 \%$, and $6 \%$ average surface slopes, respectively. Here, preferred solutions lie at the bottom of the graph. The solutions with the lowest capital cost among those in the prescribed ranges of flood volume and duration were marked in red and singled out as final sustainable drainage system designs. This corresponds to the first design preference described above. In this study, the permissible range of flood duration and volume was selected to be one-third of the range in the solution space. 
a)

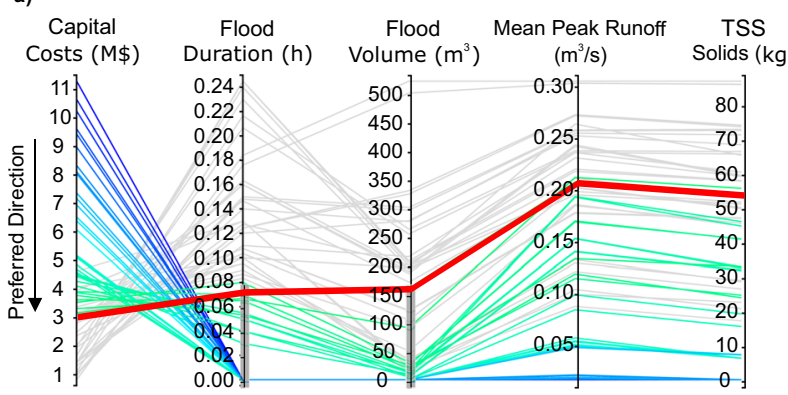

b)

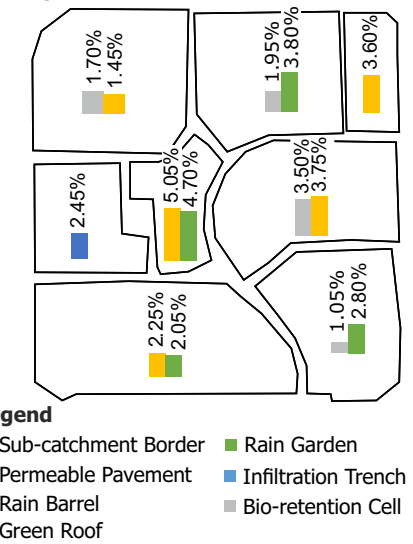

Fig. 3 Many-objective optimization of sustainable drainage infrastructure in a flat urban catchment prioritizing flood attenuation; a) objective trade-offs and selected solution (marked in red), b) types, combinations, spatial distribution, and surface areas of the selected portfolio (red line in panel (a)) described as a percentage of the respective subcatchment surface area. The grey boxes on the axes of the panel (a) are interactive filter bars, which allow urban designers to isolate a subset of efficient designs that meet their preferences

The results show the value of applying a many-objective optimization approach when there are multiple design goals that facilitate the necessary functionality of sustainable urban drainage systems. For example, in Fig. 5 it is shown that, with a $\$ 3.78$ million investment in sustainable urban drainage interventions, the total flood volume is decreased from $2,555,000 \mathrm{~m}^{3}$ to $582,000 \mathrm{~m}^{3}$ in regions with steeper surface slopes while the mean peak runoff and total suspended solids are reduced by $57 \%$ and $70 \%$, respectively. The results also imply that the average surface slope can bias the search algorithm in favor of specific types of sustainable

a)

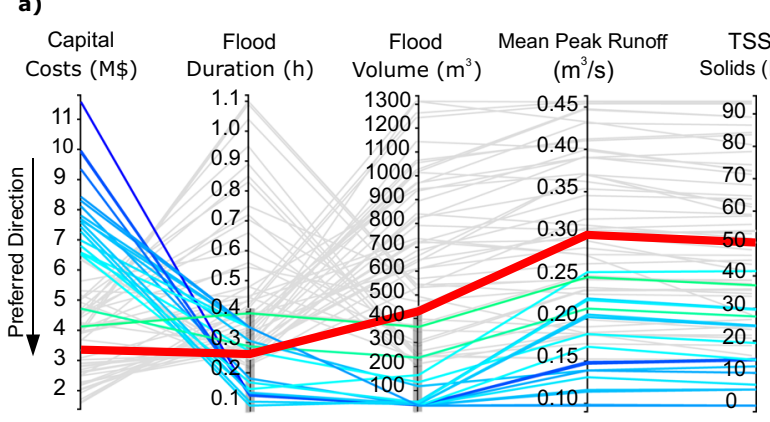

b)
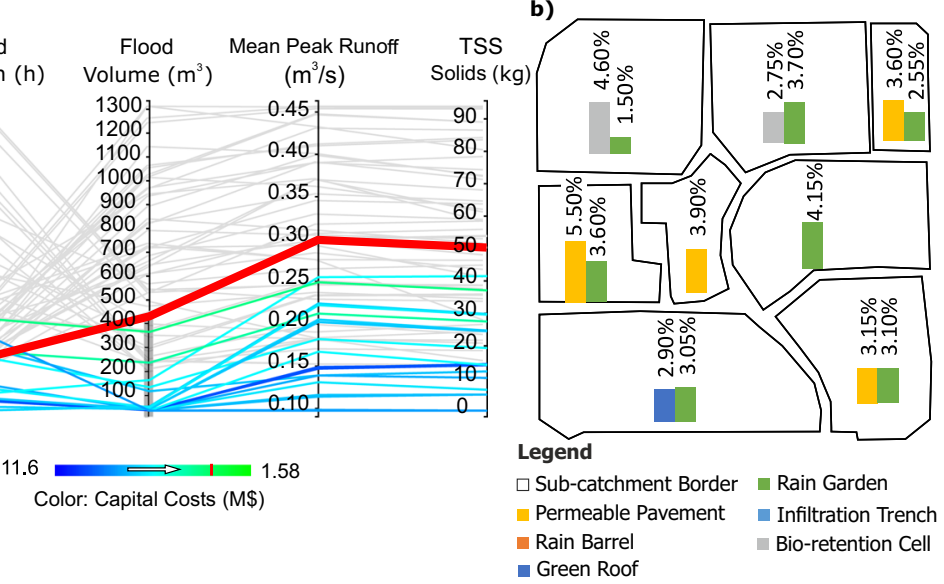

Fig. 4 Many-objective optimization of sustainable drainage infrastructure in an urban catchment with an average surface slope of $3 \%$ prioritizing flood attenuation; a) objective trade-offs and selected solution (marked in red), b) types, combinations, spatial distribution, and surface areas of the selected portfolio (red line in panel (a)) described as a percentage of the respective subcatchment surface area. The grey boxes on the axes of the panel (a) are interactive filter bars, which allow urban designers to isolate a subset of efficient designs that meet their preferences 
a)

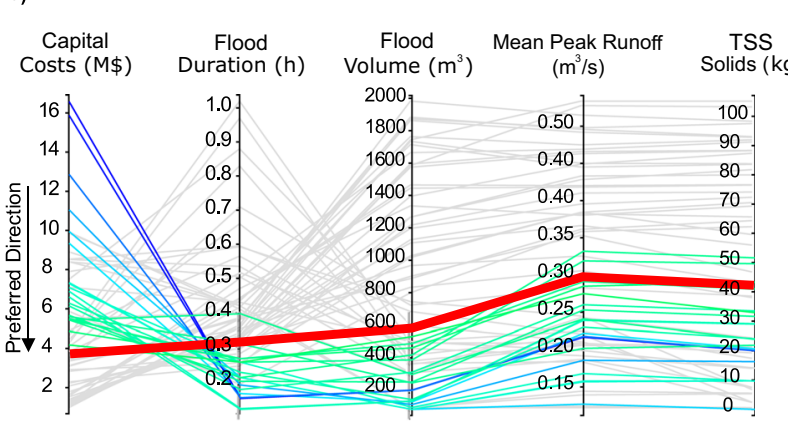

$16.6 \square \quad \Longrightarrow \quad 0.981$

Color: Capital Costs $(M \$)$ b)

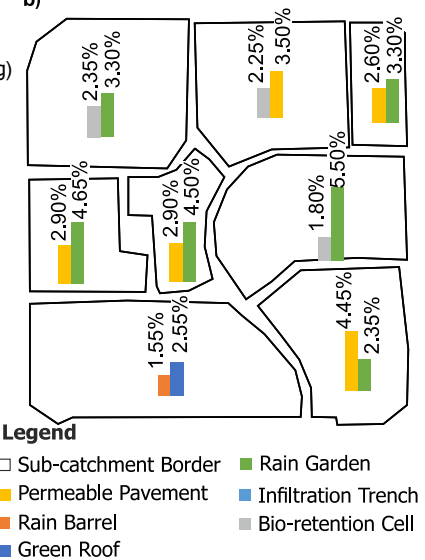

Fig. 5 Many-objective optimization of sustainable drainage infrastructure in an urban catchment with an average surface slope of $6 \%$ prioritizing flood attenuation; a) objective trade-offs and selected solution (marked in red), b) types, combinations, spatial distribution, and surface areas of the selected portfolio (red line in panel (a)) described as a percentage of the respective subcatchment surface area. The grey boxes on the axes of the panel (a) are interactive filter bars, which allow urban designers to isolate a subset of efficient designs that meet their preferences

urban drainage components. For instance, larger surface areas of rain gardens are found to be preferable in steeper slope scenarios compared to small slopes. However, no significant change was observed in surface areas of green roofs in response to changes in the surface slope, whereas the optimization suggests the use of rain barrels only for steeper surface slopes. Here, the number of barrels can be obtained based on the surface area values of interventions allocated to each subcatchment. For example, in Figs. 5 and 7, 647 rain barrels with the capacity of 1001 and L32 $\times$ W36 $\times$ H95 cm dimensions may be installed on subcatchment S5 covering a surface area of $1.55 \%$ of the subcatchment. Alternatively, underground cisterns may be used, provided that the required overall storage capacity is preserved.

Using the same procedure described above, six portfolios were extracted from the set of Pareto-optimal solutions according to the second and third set of preferences. Figure 6 depicts bar chart plots of surface areas of sustainable drainage facilities against the spatial distribution, types, and combinations of these assets in each subcatchment.

Figure 7 presents a summary sunburst diagram of the selected portfolios for different average surface slopes and design preferences. The results show that the diversity of drainage asset types is reduced as the average surface slope increases for the sets of design preferences. For example, the optimization mainly suggests rain gardens on steeper slope catchments for all preference sets. For the second preference set, Fig. 6a and Fig. 7 show that bio-retention cells are more suited for reducing the average peak runoff in the urban catchment as well as flood volume for all three slopes. Conversely, permeable pavements and rain gardens are mainly associated with catchments with lower or average slopes. For the third preference set, where the stormwater quality is prioritized, the results are biased towards green drainage facilities for all surface slope scenarios. For this set of priorities, the optimization mainly suggests bioretention cells and rain gardens on steeper slope catchments. The bias towards particular types of sustainable drainage components induced by the surface slope can potentially raise concerns regarding fairness in the spatial distribution of green drainage co-benefits. These could be mitigated by considering proper metrics of spatial equity in the optimization problem. 


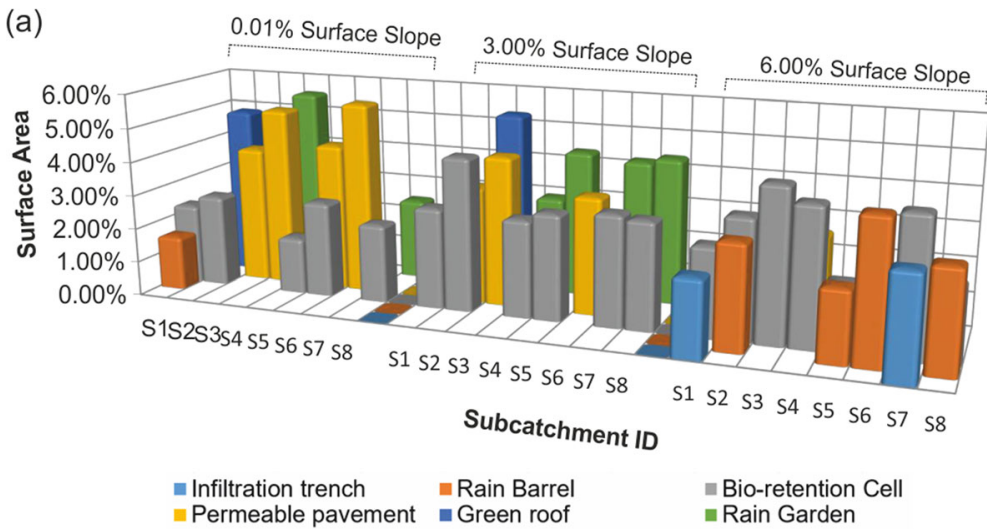

(b)

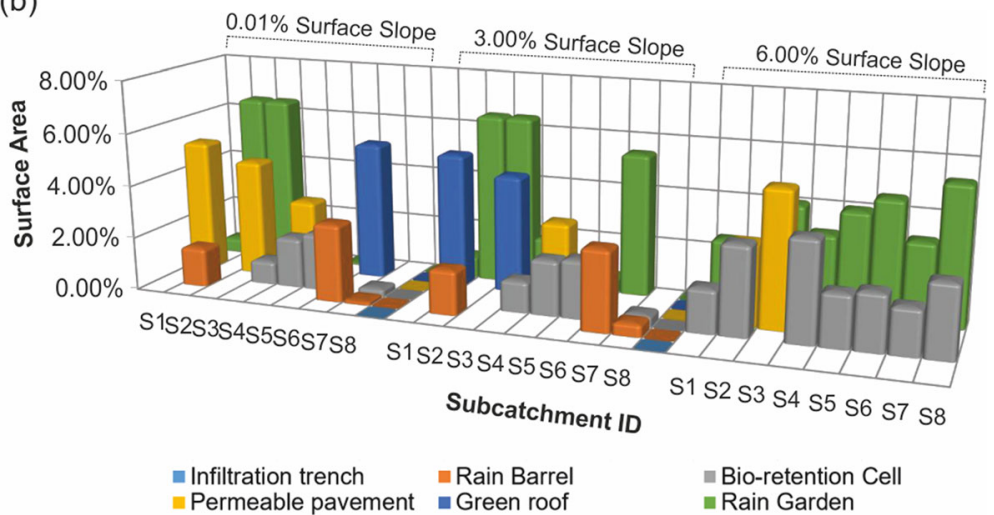

Fig. 6 Bar chart representation of the Pareto-optimal sustainable urban drainage infrastructure for each catchment surface slope scenario according to; a) the second and b) the third set of preferences

\section{Conclusions}

Urban drainage system design is a complex problem, which necessitates several performance criteria to facilitate sustainability and resilience of cities against floods. Large cities are usually characterized by spatial variations of surface slopes, affecting infiltration and detention patterns of stormwater runoff. Surface slope is an important topographic factor that can influence the efficiency of sustainable urban drainage components. This work has demonstrated the use of a many-objective optimization approach for selecting portfolios of drainage infrastructure within an urban catchment with three average surface slope scenarios. The Storm Water Management Model (SWMM) was linked to an evolutionary optimization algorithm (CNSGA-II) to search for Pareto-optimal configurations of sustainable drainage assets in several urban subcatchments interconnected by a conventional drainage network. For each subcatchment, the algorithm selects a combination of two types of drainage assets from amongst seven different options and determines the efficient surface areas of each component type by five design objectives, i.e., minimizing capital cost, flood volume, flood duration, average peak runoff, and total suspended solids. To demonstrate the selection of particular drainage designs corresponding to different trade-offs between the design objectives, the solution space was narrowed down by filtering specific optimization objectives according to 


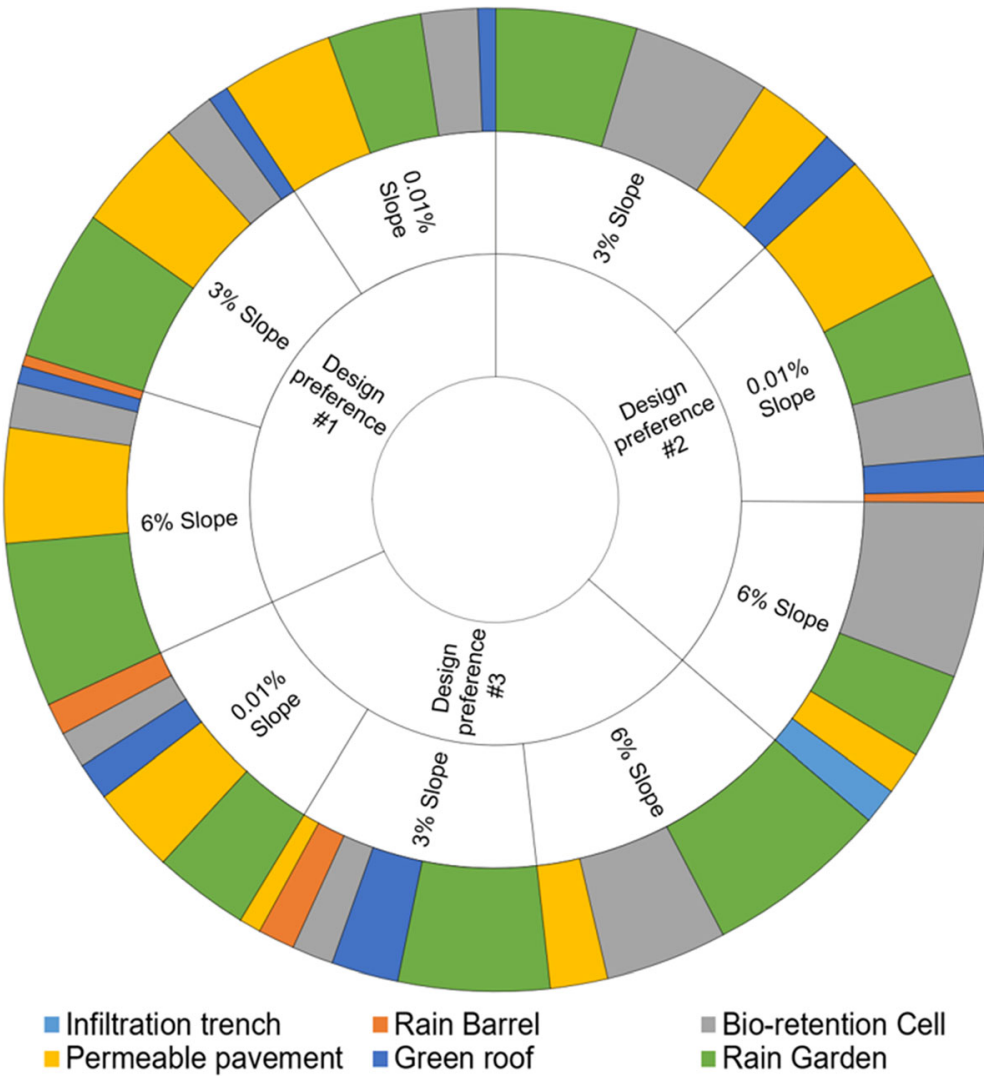

Fig. 7 Sunburst diagram summarizing surface areas of the selected sustainable urban drainage system designs for each surface slope scenario and design preference. The figure shows the impact of average surface slope on sustainable urban drainage design obtainable from an optimization model

stakeholder preferences and/or environmental constraints. Different visualization techniques were employed to analyze the results, including a novel plot where a system design schematic is placed alongside a parallel axis trade-off plot. This optimization approach was applied to urban catchments with three different slope scenarios to investigate how surface slope impacts the design of sustainable urban drainage systems. It was found that variations of surface slopes in an urban area play an important role in controlling the optimal distribution of sustainable drainage components, suggesting higher investment in green infrastructure in subcatchments with steeper surface slopes. However, since sustainable drainage assets provide a set of co-benefits for both the environment and human health, an unbalanced distribution of sustainable drainage assets in large urban areas may raise equality concerns.

The application of optimization models to large urban drainage networks is hindered by their extensive computational requirements as the optimization time increases exponentially with the number of decision variables. Future work should develop strategies for application of similar optimization approaches to larger drainage networks and consider equality and equity metrics to ensure fairness in the distribution of green infrastructure benefits. 
Acknowledgments This work was jointly supported by Thames Water Utilities Ltd. and The University of Manchester.

Funding This work was jointly supported by Thames Water Utilities Ltd. and The University of Manchester.

Availability of Data and Material Not applicable.

Code Availability The results of this work were obtained using a custom-made Matlab code and the software SWMM developed by the US Environmental Protection Agency.

\section{Declarations}

Conflicts of Interest/Competing Interests The authors declare that they have no conflict of interest in this work.

Ethics Approval Not applicable.

Consent to Participate All of the authors consent to participate in this research work.

Consent for Publication All of the authors consent to publish this work.

\section{Abbreviations}

A, Flow cross-sectional area;

a, $\quad$ Surface area of sustainable drainage assets;

c, Capital cost;

$F_{\text {Cost }}, \quad$ Capital cost objective;

$F_{\text {FloodV, }}$ Flood volume objective;

$F_{\text {FloodD, }}$ Flood duration objective;

FD, $\quad$ Flood duration;

$F V, \quad$ Flood volume;

F, Objective function vector;

g, Gravity acceleration;

$h_{L}$, Local energy loss per unit length of conduit;

l, $\quad$ Number of sustainable drainage assets;

H, Hydraulic head; 


$\begin{array}{ll}P, & \text { Peak runoff; } \\ Q, & \text { Discharge; } \\ n, & \text { Number of manholes; } \\ n_{f}, & \text { Number of flooded nodes; } \\ n_{s}, & \text { Number of subcatchments; } \\ S_{f}, & \text { Friction slope; } \\ t, & \text { Time; } \\ x, & \text { Distance; }\end{array}$

$\theta$, Vector of decision variables

Open Access This article is licensed under a Creative Commons Attribution 4.0 International License, which permits use, sharing, adaptation, distribution and reproduction in any medium or format, as long as you give appropriate credit to the original author(s) and the source, provide a link to the Creative Commons licence, and indicate if changes were made. The images or other third party material in this article are included in the article's Creative Commons licence, unless indicated otherwise in a credit line to the material. If material is not included in the article's Creative Commons licence and your intended use is not permitted by statutory regulation or exceeds the permitted use, you will need to obtain permission directly from the copyright holder. To view a copy of this licence, visit http://creativecommons.org/licenses/by/4.0/.

\section{References}

Abou Rjeily Y, Abbas O, Sadek M, Shahrour I, Hage Chehade F (2018) Model predictive control for optimising the operation of urban drainage systems. J Hydrol 566:558-565. https://doi.org/10.1016/j.jhydrol.2018.09.044

Abou Rjeily Y, Abbas O, Sadek M, Shahrour I, Hage Chehade F (2017) Flood forecasting within urban drainage systems using NARX neural network. Water Sci Technol 76:2401-2412. https://doi.org/10.2166/wst.2017.409

Alamdari N, Sample DJ (2019) A multiobjective simulation-optimization tool for assisting in urban watershed restoration planning. J Clean Prod 213:251-261. https://doi.org/10.1016/j.jclepro.2018.12.108

Alves A, Gersonius B, Kapelan Z, Vojinovic Z, Sanchez A (2019) Assessing the co-benefits of green-blue-grey infrastructure for sustainable urban flood risk management. J Environ Manag 239:244-254. https://doi.org/ 10.1016/j.jenvman.2019.03.036

Arfa S, Nasseri M, Tavakol-Davani H (2021) Comparing the effects of different daily and sub-daily downscaling approaches on the response of urban Stormwater collection systems. Water Resour Manag 35:505-533. https://doi.org/10.1007/s11269-020-02728-9

Banihabib ME, Mohammad Rezapour Tabari M, Mohammad Rezapour Tabari M (2019) Development of a fuzzy multi-objective heuristic model for optimum water allocation. Water Resour Manag 33:3673-3689. https://doi.org/10.1007/s11269-019-02323-7

Bolliger J, Silbernagel J (2020) Contribution of connectivity assessments to green infrastructure (GI). ISPRS Int J Geo-Information 9

CRC for Water Sensitive Cities (2016) Enhancing the economic evaluation of WSUD. CRCWSC Res Synth

Deb K, Goel T (2001) Controlled elitist non-dominated sorting genetic algorithms for better convergence. In: Lecture notes in computer science (including subseries lecture notes in artificial intelligence and lecture notes in bioinformatics). Springer, Berlin, Heidelberg, pp. 67-81

Deb K, Pratap A, Agarwal S, Meyarivan T (2002) A fast and elitist multiobjective genetic algorithm: NSGA-II. IEEE Trans Evol Comput 6:182-197. https://doi.org/10.1109/4235.996017 
Duan HF, Li F, Yan H (2016) Multi-objective optimal Design of Detention Tanks in the urban Stormwater drainage system: LID implementation and analysis. Water Resour Manag 30:4635-4648. https://doi.org/10. 1007/s11269-016-1444-1

Eckart K, McPhee Z, Bolisetti T (2018) Multiobjective optimization of low impact development stormwater controls. Elsevier B.V

Fleming PJ, Purshouse RC, Lygoe RJ (2005) Many-objective optimization: an engineering design perspective

Fletcher TD, Shuster W, Hunt WF, Ashley R, Butler D, Arthur S, Trowsdale S, Barraud S, Semadeni-Davies A, Bertrand-Krajewski JL, Mikkelsen PS, Rivard G, Uhl M, Dagenais D, Viklander M (2015) SUDS, LID, BMPs, WSUD and more - the evolution and application of terminology surrounding urban drainage. Urban Water J 12:525-542. https://doi.org/10.1080/1573062X.2014.916314

Geberemariam TK (2021) Green infrastructure: possible new approach or merely new terminology in Stormwater management. J Sustain Water Built Environ 7:02520003. https://doi.org/10.1061/jswbay. 0000931

Ghodsi SH, Kerachian R, Zahmatkesh Z (2016) A multi-stakeholder framework for urban runoff quality management: application of social choice and bargaining techniques. Sci Total Environ 550:574-585. https://doi.org/10.1016/j.scitotenv.2016.01.052

Ghodsi SH, Zahmatkesh Z, Goharian E, Kerachian R, Zhu Z (2020) Optimal design of low impact development practices in response to climate change. J Hydrol 580:124266. https://doi.org/10.1016/j.jhydrol.2019.124266

Giacomoni MH, Joseph J (2017) Multi-objective evolutionary optimization and Monte Carlo simulation for placement of low impact development in the catchment scale. J Water Resour Plan Manag 143:04017053. https://doi.org/10.1061/(ASCE)WR.1943-5452.0000812

Hadka D, Reed P (2013) Borg: an auto-adaptive many-objective evolutionary computing framework. Evol Comput 21:231-259. https://doi.org/10.1162/EVCO_a_00075

Horgan D, Dimitrijević B (2019) Frameworks for citizens participation in planning: from conversational to smart tools. Sustain Cities Soc 48:101550. https://doi.org/10.1016/j.scs.2019.101550

Horton B, Digman CJ, Ashley RM, Gill E (2016) BeST (benefits of SuDS tool) W045c BeST-technical guidance

Hou J, Hou B, Sun S (2019) Spatial optimization of low-impact development facilities based on a p-median model and an ant Colony optimization. J Hydrol Eng 24:04019055. https://doi.org/10.1061/(ASCE)HE. 1943-5584.0001855

Hu M, Zhang X, Siu YL, Li Y, Tanaka K, Yang H, Xu Y (2018) Flood mitigation by permeable pavements in Chinese sponge city construction. Water (Switzerland) 10:172. https://doi.org/10.3390/w10020172

Inselberg A (2009) Parallel coordinates: visual multidimensional geometry and its applications. Springer New York, New York, NY

Khorshidi MS, Nikoo MR, Sadegh M (2018) Optimal and objective placement of sensors in water distribution systems using information theory. Water Res 143:218-228. https://doi.org/10.1016/j.watres.2018.06.050

Latifi M, Rakhshandehroo G, Nikoo MR, Sadegh M (2019) A game theoretical low impact development optimization model for urban storm water management. J Clean Prod 241:118323. https://doi.org/10. 1016/j.jclepro.2019.118323

Leng L, Jia H, Chen AS, Zhu DZ, Xu T, Yu S (2021) Multi-objective optimization for green-grey infrastructures in response to external uncertainties. Sci Total Environ 775:145831. https://doi.org/10.1016/j.scitotenv.2021.145831

Li F, Duan HF, Yan H, Tao T (2015) Multi-objective optimal Design of Detention Tanks in the urban Stormwater drainage system: framework development and case study. Water Resour Manag 29:21252137. https://doi.org/10.1007/s11269-015-0931-0

Li F, Yan XF, Duan HF (2019) Sustainable Design of Urban Stormwater Drainage Systems by implementing detention tank and LID measures for flooding risk control and water quality management. Water Resour Manag 33:3271-3288. https://doi.org/10.1007/s11269-019-02300-0

Lu W, Qin X (2019) An integrated fuzzy simulation-optimization model for supporting low impact development design under uncertainty. Water Resour Manag 33:4351-4365. https://doi.org/10.1007/s11269-019-02377-7

Luodan Y, Te X, Xuhui M, Haifeng J (2019) Site-scale LID-BMPs planning and optimization in residential areas. J Sustain Water Built Environ 5:5018004. https://doi.org/10.1061/JSWBAY.0000870

Macro K, Matott LS, Rabideau A, Ghodsi SH, Zhu Z (2019) OSTRICH-SWMM: a new multi-objective optimization tool for green infrastructure planning with SWMM. Environ Model Softw 113:42-47. https://doi.org/10.1016/j.envsoft.2018.12.004

Manocha N, Babovic V (2018) Real options, multi-objective optimization and the development of dynamically robust adaptive pathways. Environ Sci Pol 90:11-18. https://doi.org/10.1016/j.envsci.2018.09.012

Martínez C, Sanchez A, Toloh B, Vojinovic Z (2018) Multi-objective evaluation of urban drainage networks using a 1D/2D flood inundation model. Water Resour Manag 32:4329-4343. https://doi.org/10.1007/ s1 1269-018-2054-x 
Raei E, Reza Alizadeh M, Reza Nikoo M, Adamowski J (2019) Multi-objective decision-making for green infrastructure planning (LID-BMPs) in urban storm water management under uncertainty. J Hydrol 579: 124091. https://doi.org/10.1016/j.jhydrol.2019.124091

Riaño-Briceño G, Barreiro-Gomez J, Ramirez-Jaime A, Quijano N, Ocampo-Martinez C (2016) MatSWMM - an open-source toolbox for designing real-time control of urban drainage systems. Environ Model Softw 83: 143-154. https://doi.org/10.1016/j.envsoft.2016.05.009

Rossman LA (2017) Storm water management model reference manual - hydraulics. US EPA Office of Research and Development, Washington, DC

Rossman LA, Huber WC (2016) Storm water management model reference manual volume III - water quality. U.S. Environmental Protection Agency, Washington, DC

Taghizadeh S, Khani S, Rajaee T (2021) Hybrid SWMM and particle swarm optimization model for urban runoff water quality control by using green infrastructures (LID-BMPs). Urban For Urban Green 60:127032. https://doi.org/10.1016/j.ufug.2021.127032

Taguchi VJ, Weiss PT, Gulliver JS, Klein M, Hozalski R, Baker L, Finlay J, Keeler B, Nieber J (2020) It is not easy being green: recognizing unintended consequences of green stormwater infrastructure. Water (Switzerland) 12:522. https://doi.org/10.3390/w12020522

Tang S, Jiang J, Zheng Y, Hong Y, Chung ES, Shamseldin AY, Wei Y, Wang X (2021) Robustness analysis of storm water quality modelling with LID infrastructures from natural event-based field monitoring. Sci Total Environ 753:142007. https://doi.org/10.1016/j.scitotenv.2020.142007

Washington State Department of Ecology, Herrera Environmental Consultants (2012) PugetSound Stormwater BMP cost database. Herrera Environmental Consultants, Inc., Washington

Xu H, Ma C, Xu K, Lian J, Long Y (2020) Staged optimization of urban drainage systems considering climate change and hydrological model uncertainty. J Hydrol 587:124959. https://doi.org/10.1016/j.jhydrol.2020. 124959

Xu T, Engel BA, Shi X, Leng L, Jia H, Yu SL, Liu Y (2018) Marginal-cost-based greedy strategy (MCGS): fast and reliable optimization of low impact development (LID) layout. Sci Total Environ 640-641:570-580. https://doi.org/10.1016/j.scitotenv.2018.05.358

Yang W, Zhang J (2021) Assessing the performance of gray and green strategies for sustainable urban drainage system development: a multi-criteria decision-making analysis. J Clean Prod 293:126191. https://doi.org/10. 1016/j.jclepro.2021.126191

Zatarain Salazar J, Reed PM, Quinn JD, Giuliani M, Castelletti A (2017) Balancing exploration, uncertainty and computational demands in many objective reservoir optimization. Adv Water Resour 109:196-210. https:// doi.org/10.1016/j.advwatres.2017.09.014

Zhang K, Bach PM, Mathios J, Dotto CBS, Deletic A (2020) Quantifying the benefits of stormwater harvesting for pollution mitigation. Water Res 171:115395. https://doi.org/10.1016/j.watres.2019.115395

Zheng Z, Shen W, Li Y, Qin Y, Wang L (2020) Spatial equity of park green space using KD2SFCA and web map API: a case study of Zhengzhou, China. Appl Geogr 123:102310. https://doi.org/10.1016/j.apgeog. 2020.102310

Publisher's Note Springer Nature remains neutral with regard to jurisdictional claims in published maps and institutional affiliations. 